\title{
Compartmentalization of Information Processing in an Aplysia Feeding Circuit Interneuron through Membrane Properties and Synaptic Interactions
}

\author{
Ray Perrins and Klaudiusz R. Weiss \\ Department of Physiology and Biophysics, Mount Sinai School of Medicine, Mount Sinai Medical Center, \\ New York, New York 10029-6574
}

We describe a pair of cerebral-to-buccal interneurons, CBI-5/6, which have outputs and inputs in two ganglia. The soma in the cerebral ganglion received synaptic inputs during buccal motor programs (BMPs) and after mechanical stimulation of the lips. During BMPs the soma received antidromic spikes generated in processes in the buccal ganglion. The soma was driven into a plateau potential by each of these inputs, during which it fired orthodromically at $0-5 \mathrm{~Hz}$. The soma had outputs in the cerebral ganglion consisting of electrical coupling to the adjacent $\mathrm{CBI}-5 / 6$ and to a cerebral-to-pedal neuron (CPN1). The buccal terminals of $\mathrm{CBI}-5 / 6$ received inputs that generated rhythmic barrages (up to $25 \mathrm{~Hz}$ ) of antidromic spikes during BMPs. The buccal terminals had chemical and electrical outputs to motor and premotor elements of feeding circuitry. This combination of synaptic interactions and endogenous properties mean that

The traditional view of information flow through a neuron comprises input to the soma and dendrites summating to produce all-or-none action potentials that then travel down the axon and result in output through transmitter release at distal terminals. Recently, however, it has become apparent that in several systems the processing of information by neurons is not necessarily strictly limited to a single "input-output" pathway. Distinct anatomical parts of a neuron may differentially integrate and relay information using different mechanisms. Such compartmentalization is important in neuronal circuits because it theoretically allows information flow in different parts of a neuron to be dissociated under some conditions but enables the neuron to act as a single unit under other conditions. In both the stomatogastric nervous system (Hartline and Graubard, 1992) and Aplysia neurons B31/32 (Hurwitz et al., 1994) there are examples of neurons that use conventional action potentials to perform peripheral motoneuronal functions while simultaneously performing central interneuronal functions through plateau potentials generated in the ganglia. In these neurons the effects of plateau potential and the generation of conventional spikes are not completely inde-

Received Nov. 13, 1997; revised March 3, 1998; accepted March 6, 1998.

This work was supported by the Human Frontiers Science Program Grant LT561/95 and National Institutes of Health Grants GM 32009 and MH 50235. We thank Dr. Paul Church for extremely valuable comments on this manuscript.

Correspondence should be addressed to Klaudiusz R. Weiss, Department of Physiology and Biophysics, Mount Sinai School of Medicine, Mount Sinai Medical Center, One Gustave L. Levy Place, New York, NY 10029-6574.

Dr. Perrins's present address: School of Biological Sciences, University of Bristol, Woodland Road, Bristol, BS8 1UG, United Kingdom.

Copyright (C) 1998 Society for Neuroscience $0270-6474 / 98 / 183977-13 \$ 05.00 / 0$
$\mathrm{CBI}-5 / 6$ can process information in a number of ways. During the barrage of antidromic spikes, high-frequency firing will produce strong inputs to buccal followers and on their arrival at the soma will transfer excitation electrotonically to CPN1. Subthreshold input to the soma will be transferred electrotonically to cerebral followers but will not be relayed to postsynaptic buccal neurons. Plateau potentials after the antidromic spikes or local cerebral inputs will locally excite CPN1 via electrical coupling but will have little influence on buccal events because of the low orthodromic firing rate. Thus, $\mathrm{CBI}-5 / 6$ may transmit information locally within the cerebral ganglion or more extensively in both buccal and cerebral ganglia simultaneously.

Key words: plateau potential; feeding; mollusk; motor program; central pattern generator; Aplysia

pendent, because the frequency of action potentials depends on the characteristics of the plateau potential.

In the stomatogastric system there are also examples of neurons with axons or terminals that receive inputs different from those received at the soma. For example, transmission of spikes generated in the soma of motoneuron OD1 (in the esophageal ganglion) can be rhythmically blocked in the commissural ganglion (Nagy et al., 1981). In the same system, the outputs of interganglionic interneuron MCN1 at its stomatogastric ganglion terminals can be inhibited by different inputs from those influencing the soma, located in the commissural ganglion (Nusbaum et al., 1992; Coleman and Nusbaum, 1994; Coleman et al., 1995).

Extending these concepts, we report here that in Aplysia californica interganglionic neurons $\mathrm{CBI}-5 / 6$ can process information separately in two ganglia. In CBI-5/6 the segregation is more complete than for OD1 and MCN1, because output from the soma of CBI-5/6 in the cerebral ganglion can be controlled independently of output from the terminals in the buccal ganglion. The soma and terminals can also act as a single unit under other circumstance. Because different ganglia often subserve specialized functions, this type of organization may be advantageous for controlling distinct but related components of a behavior. An important feature of the functional separation within CBI-5/6 is the demonstration of how plateau potentials in the soma of a neuron can be almost completely dissociated from spiking in the axon.

In this paper we present evidence that the CBI-5/6 are part of the consumatory feeding circuit of Aplysia. We then describe a number of specific characteristics of these neurons (including the ability to generate plateau potentials, to initiate action potentials in two ganglia, and to use both chemical and electrical transmis- 
sion) that combine to create a functional separation of anatomically distinct parts of $\mathrm{CBI}-5 / 6$, endowing them with the ability to segregate their inputs and outputs, both spatially and temporally.

\section{MATERIALS AND METHODS}

Experiments were performed on Aplysia californica weighing 100-300 $\mathrm{gm}$. Animals were anesthetized by injection of isotonic $\mathrm{MgCl}_{2}(50 \%$ of body weight) into the body cavity. The cerebral ganglion was dissected out in isolation for some experiments and removed with the buccal ganglion attached for others (see Results for details). The ganglia were pinned onto a Sylgard-coated dish at room temperature in artificial seawater (ASW). Cerebral ganglia were pinned ventral surface up, and buccal ganglia were pinned rostral surface up. The connective tissue overlying the uppermost surface of each ganglia was surgically removed. The cerebral-to-pedal connective was rotated through $180^{\circ}$ and repinned to allow access to the lateral area of the E-cluster. Simultaneous intracellular recordings were made from up to four neurons using single- or double-barreled microelectrodes filled with $2 \mathrm{~m}$ potassium acetate and beveled to a resistance ranging from 5 to $10 \mathrm{M} \Omega$, depending on the size of the cell to be penetrated. In preparations in which the buccal ganglion was attached, buccal motor output was monitored using a polyethylene suction electrode placed over buccal nerve 2 (Morton and Chiel, 1993) and connected to an AC amplifier. A recording or stimulating suction electrode was placed over the end of the severed cerebral-to-buccal connective $(\mathrm{CBC})$ in experiments involving isolated cerebral ganglia.

To help identify previously described cells and to reveal the morphology of new ones, microelectrodes, beveled to a resistance of $10-15 \mathrm{M} \Omega$, were filled with a $3 \%$ solution of 5(6)-carboxyfluorescein in $0.1 \mathrm{M}$ potassium citrate, titrated to $\mathrm{pH} 8.0$ with $\mathrm{KOH}$ (Rao et al., 1986). At the end of each experiment, previously described cells were identified on the basis of their morphology and known synaptic connections. In some experiments polysynaptic pathways were suppressed using solutions containing elevated levels of divalent cations (with both $\mathrm{Ca}^{2+}$ and $\mathrm{Mg}^{2+}$ at three times normal concentration) to raise neuronal firing thresholds.

To determine the response of CBI-5/6 to feeding-related stimuli, experiments were performed on preparations in which the cerebral ganglion was removed with the lips and anterior tentacles still attached by their peripheral nerves. The ganglion was pinned on an elevated Sylgard platform, ventral surface uppermost, and desheathed as described above. The head structures were pinned, ventral surface uppermost, to the bottom of the Sylgard-coated dish in such a way as to reveal the inner portions of the lips and perioral zone (Rosen et al., 1982). The anterior aorta was cannulated and perfused with ASW. Mechanical stimuli were applied using a firepolished Pasteur pipette with a tip diameter of $\sim 1 \mathrm{~mm}$ (Rosen et al., 1991b). Chemical stimuli consisting of seaweed extract in ASW, filtered through a $0.8 \mu \mathrm{m}$ Millipore filter unit.

Salines, all at $\mathrm{pH} 7.6$, were composed as follows: ASW (in mM): 460 $\mathrm{NaCl}, 10 \mathrm{KCl}, 11 \mathrm{CaCl}_{2}, 55 \mathrm{MgCl}_{2}$, and $5 \mathrm{NaHCO}_{3}$; high-divalent saline $\left(3 \times \mathrm{Mg}^{2+}\right.$ and $\left.3 \times \mathrm{Ca}^{2+}\right): 460 \mathrm{NaCl}, 10 \mathrm{KCl}, 33 \mathrm{CaCl}_{2}, 165 \mathrm{MgCl}_{2}$, and $5 \mathrm{NaHCO}_{3}$; $\mathrm{Ca}^{2+}$-free saline: $460 \mathrm{NaCl}, 10 \mathrm{KCl}, 11 \mathrm{CaCl}_{2}, 66 \mathrm{MgCl}_{2}$, $5 \mathrm{NaHCO}_{3}$, and 1 EGTA; and $\mathrm{Na}^{+}$-free saline: $460 \mathrm{~N}$-methyl-Dglucamine, $10 \mathrm{KCl}, 11 \mathrm{CaCl}_{2}, 55 \mathrm{MgCl}_{2}$, and $5 \mathrm{NaHCO}_{3}$. In some experiments (see Results for details) $11 \mathrm{mM} \mathrm{Co}^{2+}$ was added to $\mathrm{Ca}^{2+}$. free saline. Experiments were performed at least six times, unless otherwise stated. Figures quoted are mean \pm SEM.

\section{RESULTS}

\section{Morphology and electrophysiological properties of $\mathrm{CBI}-5 / 6$}

CBI-5/6 are a pair of cerebral neurons that are indistinguishable in both morphology and physiology. Injections of 5(6)carboxyfluorescein into the soma revealed CBI-5/6 as a pair of oval neurons $\sim 25-40 \mu \mathrm{m}$ in diameter adjacent to each other in the E-cluster (Jahan-Parwar and Fredman, 1979). Each had a single axon projecting into the ipsilateral CBC (Fig. $1 A$ ) and only a few short processes in the cerebral ganglion, limited to $\sim 50 \mu \mathrm{m}$ of the cell body (Fig. $1 B$ ). In the buccal ganglion the axon crossed the buccal commissure and gave rise to many short branches in both hemiganglia (Fig. 1C). No processes were observed leaving the buccal ganglion, so like CBI-1-4 these are interganglionic interneurons.

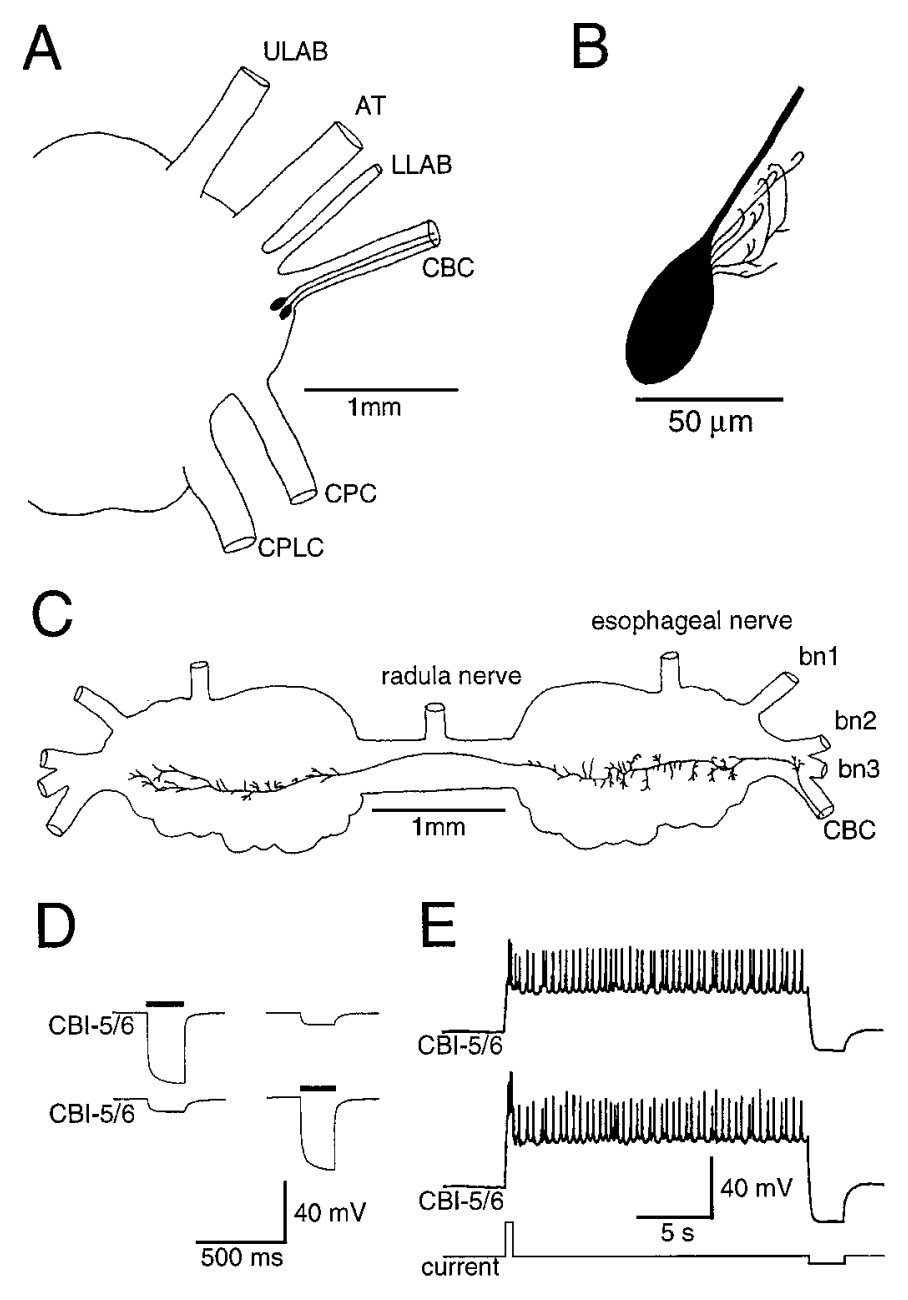

Figure 1. Morphological and electrical properties of CBI-5/6. A, Drawing of the right cerebral hemiganglion, showing the position of both right CBI-5/6 somata in the E-cluster and axons in the CBC. B, Highermagnification drawing of the soma of a single CBI-5/6 filled by intracellular injection of 5(6)-carboxyfluorescein, illustrating the oval shape of the cell body and short dendrites. $C$, Drawing of the buccal processes of CBI-5/6, showing the axon arriving from the $\mathrm{CBC}$, crossing the buccal commissure, and terminating in the contralateral hemiganglion. There were short processes in both buccal hemiganglia. $D$, Each ipsilateral CBI-5/6 was electrically coupled to the other. Negative current injected into either cell (solid bars) produced a smaller hyperpolarization in the other. $E$, A brief depolarizing current pulse (bottom trace) into one CBI-5/6 (middle trace) resulted in depolarization and firing in both ipsilateral CBI-5/6s, followed by a plateau potential in both cells. During the plateau potential, the membrane potential remained constant and both cells fired at low frequency $(\sim 2.5 \mathrm{~Hz})$. The plateau in both cells was terminated by a hyperpolarizing current pulse in one CBI-5/6. ULAB, Upper labial nerve; $A T$, anterior tentacular nerve; $L L A B$, lower labial nerve; $C B C$, cerebral-to-buccal connective; $C P C$, cerebral-to-pedal connective; $C P l C$, cerebral-to-pleural connective; $b n$, buccal nerve.

CBI-5/6 had quite distinct electrophysiological properties from neighboring E-cluster neurons. The mean resting potential was $-57.3 \pm 4.1 \mathrm{mV}(n=13)$. The two ipsilateral CBI-5/6s were electrically coupled to each other so that either positive or negative current injected into one cell resulted in a smaller membrane potential change of the same polarity, but reduced magnitude, in the other (Fig. 1D). Coupling ratios (membrane potential change in the postsynaptic cell divided by membrane potential change in the other) were $0.15: 0.25$. CBI-5/6 also possessed the ability to generate plateau potentials (Fig. $1 E$ ). CBI-5/6 could be 

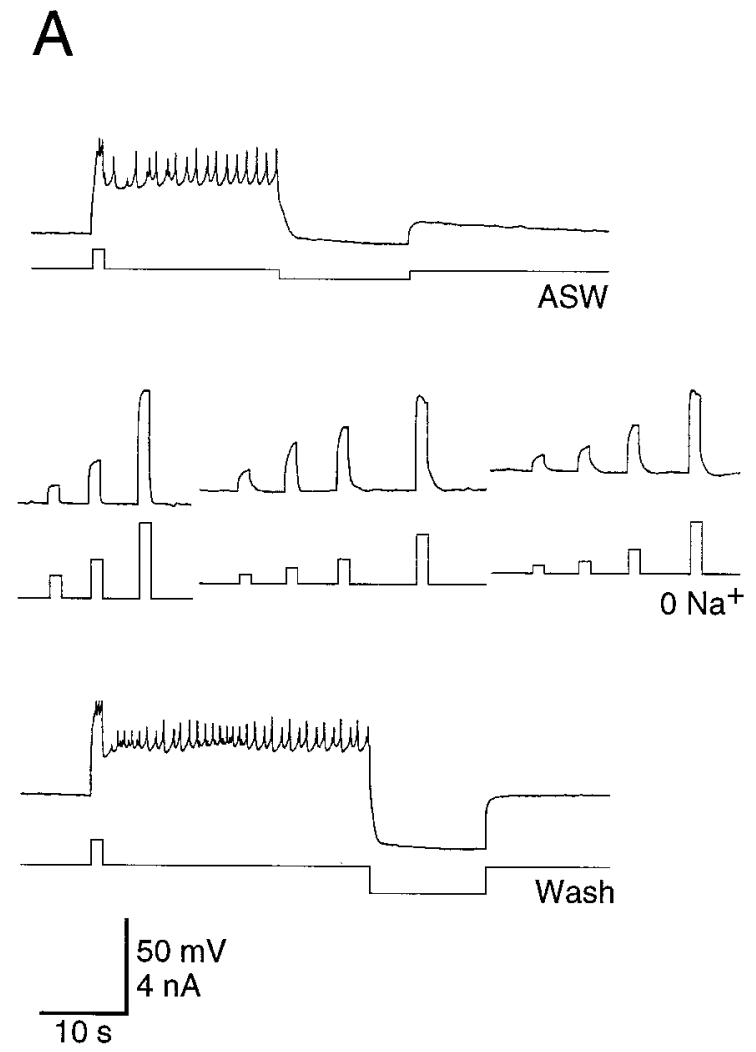

C

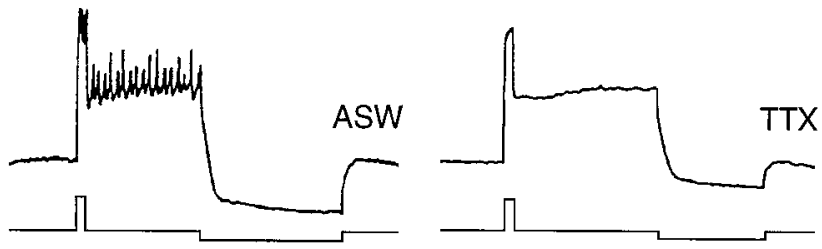

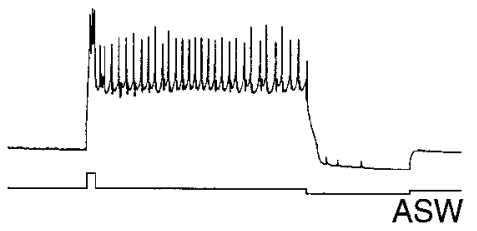
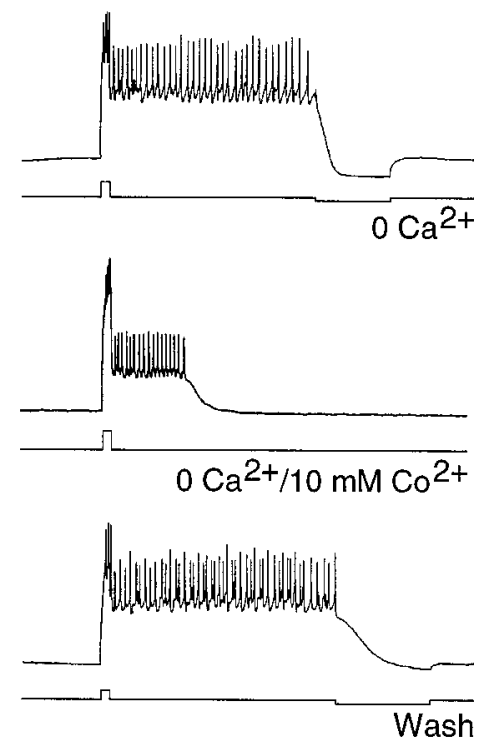

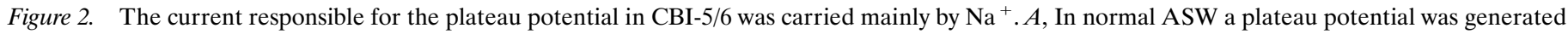

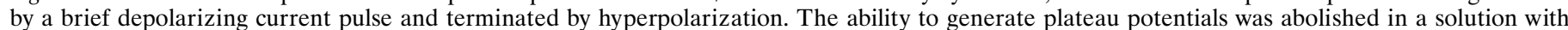

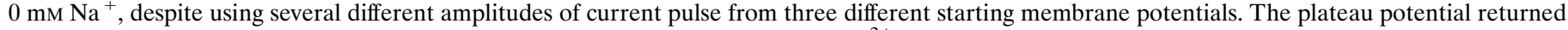

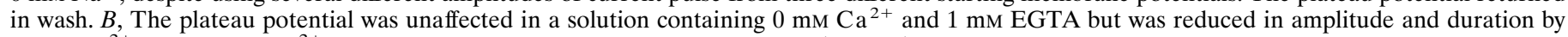

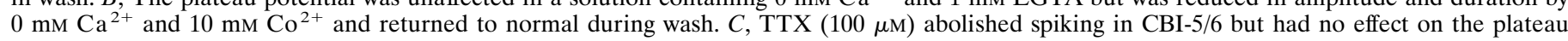
potential. Some action potentials return during wash. The scale is the same in all sections.

driven into a plateau potential after various stimuli. Most simply, a brief depolarizing current pulse injected into CBI-5/6 could lead to a sustained depolarization that was usually accompanied by the firing of action potentials. These were true plateau potentials, rather than long afterdepolarizations, according to the criteria of Hartline and Graubard (1992), because (1) the plateau potential could be terminated early by a brief hyperpolarizing current pulse, which resulted in the membrane potential returning to rest (Figs. 1E, 2); and (2) both triggering and terminating pulses result in "all-or-none" responses, the magnitudes of which are not affected by the amplitude or duration of the pulse, as long as it exceeded threshold.

The generation of a plateau potential (current threshold for plateau potentials was $0.82 \pm 0.19 \mathrm{nA}$ ) in one CBI-5/6 resulted in a similar plateau potential in the other (Fig. $1 E$ ), presumably attributed to strong electrical coupling. Likewise, when the plateau potential was terminated in one CBI-5/6, the other also reverted to the resting state. However, in most experiments spikes were not synchronous in each cell, either during positive current injection or during the plateau potential. Instead spikes in one cell were reflected by brief spike-like depolarizations in the other. The amplitude of the true action potentials in CBI-5/6 was quite small (5-20 mV; Figs. 1E, 2) and may be caused by an inexcitable soma, a feature seen in another pair of plateau-generating neurons in Aplysia, B31/B32 (Hurwitz et al., 1994). The frequency of orthodromic firing in individual CBI-5/6s was usually quite low during the plateau potential (maximum $5 \mathrm{~Hz}$ ), and occasionally few or no spikes were observed (see Fig. $7 A$ ).

\section{Mechanism of plateau potential generation}

Plateau potentials are often the result of the activation of a slow, voltage-sensitive inward current, so we investigated the ionic requirements for the maintenance of the plateau in CBI-5/6. When the ASW bathing the cerebral ganglion was replaced with 

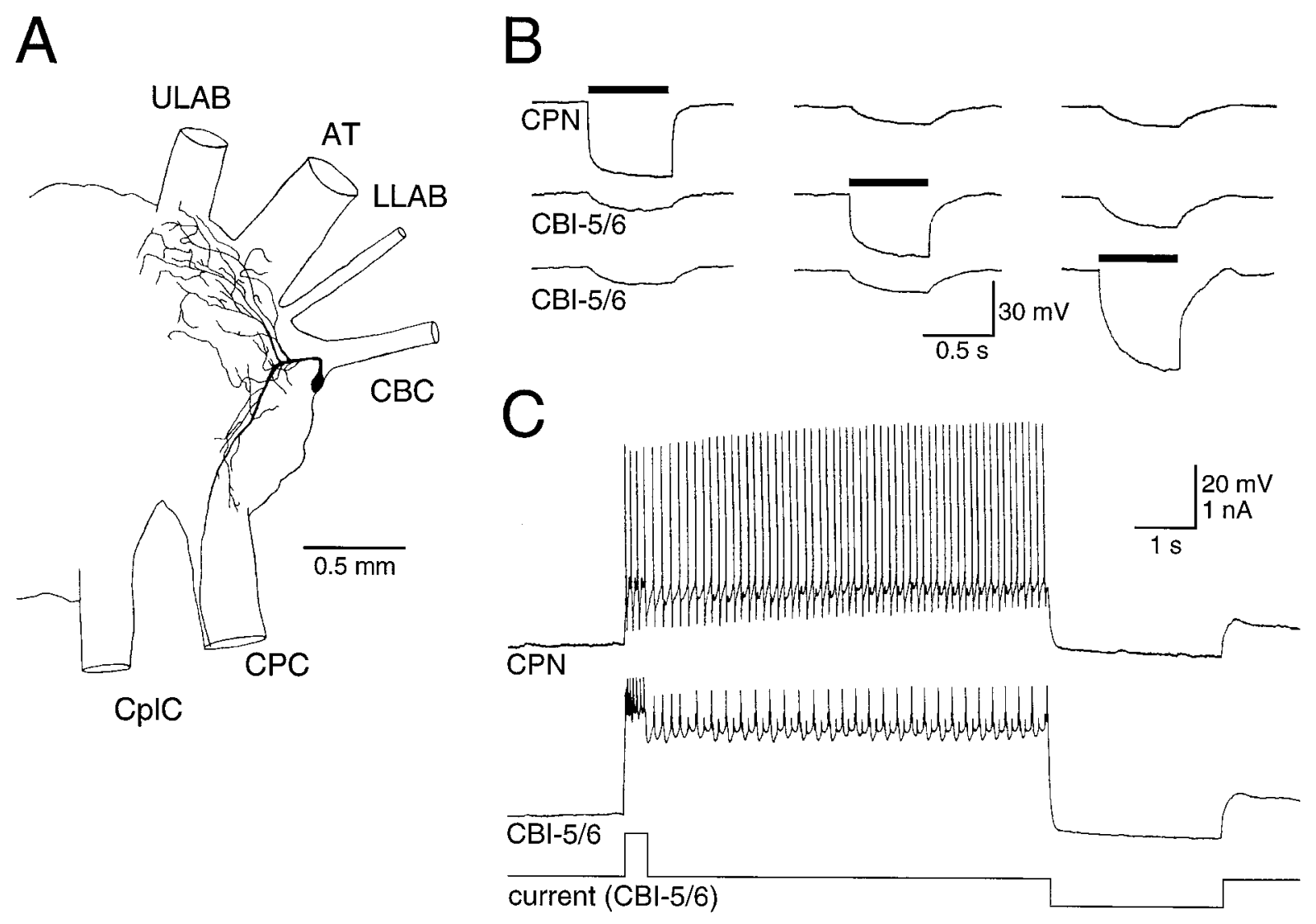

Figure 3. CBI-5/6 was strongly electrically coupled to a neighboring cerebral-to-pedal neuron (CPN1). $A$, Morphology of CPN1, which had extensive branches in the cerebral ganglion, and an axon leaving via the CPC. B, Negative current (solid bars) injected into each of the CBI-5/6s or CPN1 produced a smaller hyperpolarization in the other two cells. $C$, Driving a plateau by current injection into CBI-5/6 depolarized CPN1 above firing threshold.

a solution containing $0 \mathrm{Na}^{+}$, the plateau potentials could no longer be generated (Fig. $2 A$ ). Indeed no regenerative membrane properties were observed under these conditions, despite using a range of current pulse amplitudes and durations from a variety of initial membrane potentials. However, the plateau potential was not affected when the ASW was replaced with a solution containing nominally $0 \mathrm{Ca}^{2+}$ and $1 \mathrm{~mm}$ EGTA (Fig. $2 B$ ). In solutions containing zero $\mathrm{Ca}^{2+}$ and $11 \mathrm{mM} \mathrm{Co}^{2+}$ (a potent $\mathrm{Ca}^{2+}$ channel blocker) the plateau potential was reduced in both duration and amplitude (Fig. $2 B$ ). Assuming that $\mathrm{Co}^{2+}$ does not have nonspecific effects on $\mathrm{Na}^{+}$channels, these results indicate that the current responsible for maintaining the plateau potential is carried predominantly by $\mathrm{Na}^{+}$, although some $\mathrm{Ca}^{2+}$ entry may be required to generate the full plateau potential. The plateau potential was also not affected by bathing the ganglion in ASW containing $100 \mu \mathrm{M}$ TTX (Fig. $1 C$ ), a concentration that abolished fast action potentials in CBI-5/6 as well as the full-sized spikes in neighboring neurons. Because the plateau potential is still present in solutions with TTX or zero $\mathrm{Ca}^{2+}$, this suggests it is an endogenous property of CBI-5/6 and does not require transmitter release from other neurons.

\section{Local cerebral interactions of $\mathrm{CBI}-5 / 6$}

To better characterize CBI-5/6, we investigated the connections it makes within the Aplysia feeding system, both with individual neurons and with networks responsible for generating feedingrelated motor programs. In this section we will describe interactions with neurons in the cerebral ganglion, in which the soma of
CBI-5/6 is located. In the following section we will detail connections with neurons and circuitry in the buccal ganglion, in which CBI-5/6 has numerous distal processes.

\section{Electrical coupling}

As well as being coupled to each other, each CBI-5/6 was strongly electrically coupled to a neighboring E-cluster cell (coupling ratio, 0.25:0.40; Fig. 3B). Injections of 5(6)-carboxyfluorescein revealed a cell body approximately the same size as CBI-5/6 and in a similar location. However, this neuron had an axon projecting to the cerebral-to-pedal connective rather than the $\mathrm{CBC}$ and had extensive dendritic branching in both the E- and M-clusters (Fig. $3 A$ ). Until more formal nomenclature exists, we will refer to this neuron as cerebral-pedal neuron (CPN1). During plateau potentials in CBI-5/6, CPN1 was driven above threshold by the electrotonic transfer of excitation (Fig. $3 C$ ). When neurons are electrically coupled in this way, it is difficult to determine which neurons actually have the potential to generate plateau potentials, and which are passive followers. We found that from rest, a brief positive current could produce characteristic regenerative responses in $\mathrm{CBI}-5 / 6$, regardless of the membrane potential of CPN1 (Fig. 4A). However, if CBI-5/6 was hyperpolarized, current injected into $\mathrm{CPN} 1$ no longer possessed any regenerative properties (Fig. 4B). From this we conclude that the CBI-5/6 neurons possess the currents responsible for generating plateau potentials, whereas CPN1 passively follows these responses because of the tight electrical coupling. 


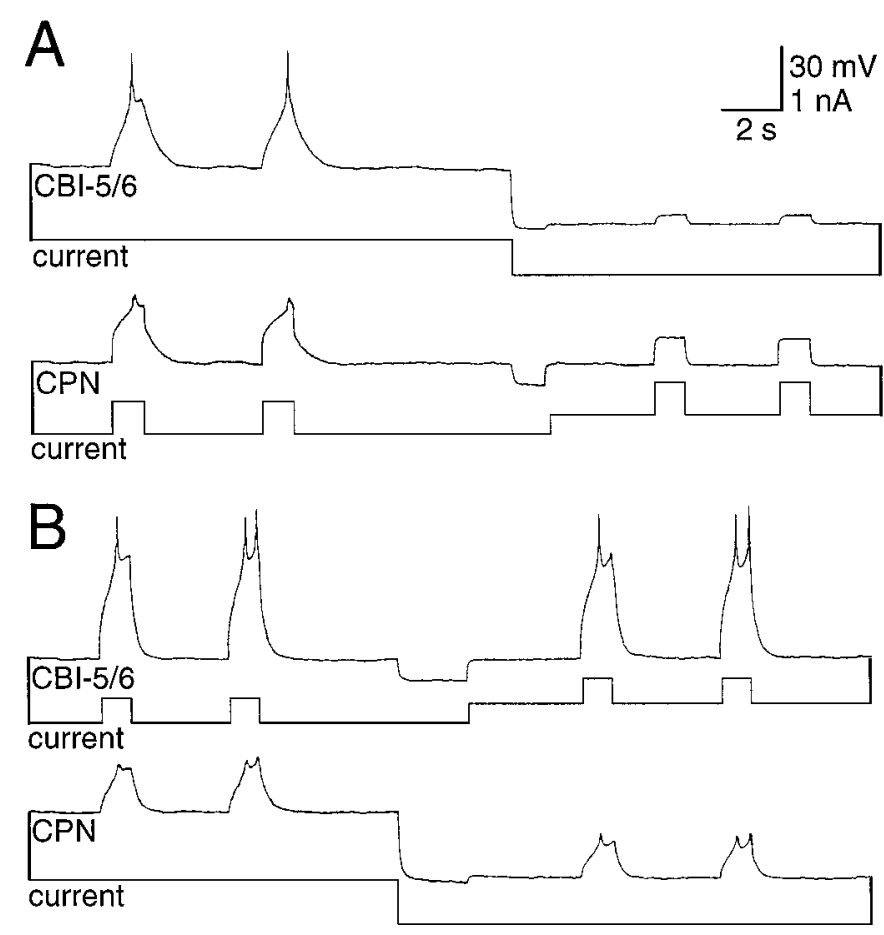

Figure 4. CBI-5/6, but not CPN1, had regenerative membrane properties. $A$, Positive current pulses injected into CPN1 depolarized both $\mathrm{CPN} 1$ and $\mathrm{CBI}-5 / 6$ with indications in both of regenerative membrane properties. CBI-5/6 was then hyperpolarized, and CPN1 brought back to the resting potential. Current injected into CPN1 now produced a passive depolarization in both neurons. $B$, Brief positive current injected into CBI-5/6 depolarized both CPN1 and CBI-5/6 with indications in both of regenerative membrane properties. CPN1 was then hyperpolarized, and CBI-5/6 brought back to the resting potential. The depolarizations in both neurons during current injection still had regenerative characteristics.

\section{Input from the lips}

To investigate the types of feeding-related stimuli to which CBI$5 / 6$ respond, we recorded from these neurons in a preparation consisting of the cerebral ganglion with the head and lips attached via the anterior tentacular and lower and upper labial nerves (Rosen et al., 1991b). We found that chemical stimuli applied to either the tentacles or lips had no effect on CBI-5/6, although, as reported previously (Rosen et al., 1991b), such stimuli strongly excited CBI-2 (Fig. 5C). However, gentle mechanical stimulation of the inner lips excited CBI-5/6 into a plateau potential, although only briefly stimulating CBI-2 (Fig. $5 D$ ). The plateau continued until terminated by negative current. When CBI-5/6 was hyperpolarized by constant negative current this excitation was observed to consist of fast and slow EPSPs. When both cerebral and buccal ganglia were present, similar responses in CBI-5/6 were observed, suggesting that this excitation is mediated largely by cerebral neurons. [In such preparations patterned input was also sometimes observed because of buccal feedback when a buccal motor program (BMP) was elicited; see below].

$\mathrm{C} 2$ is a cerebral mechanoafferent for the inner lips and makes widespread connections with cerebral feeding circuitry (Chiel et al., 1986; Weiss et al., 1986). Input from C2 to CBI-5/6 consisted of a biphasic fast and slow excitation, which persisted in high divalents (Fig. $5 A$ ). If $\mathrm{C} 2$ fired for longer than $\sim 1 \mathrm{sec}$, the slow excitatory phase could drive CBI-5/6 into the plateau potential, which could subsequently be terminated by negative current (Fig. $5 B$ ). Interganglionic cerebral-buccal mechanoafferents (ICBMs) are another class of lip mechanoreceptors (Rosen et al., 1982). We identified ICBMs in a number of preparations by the monosynaptic EPSPs they produce in CBI-1 (Rosen et al., 1991b), but in no case could any connection be found with CBI-5/6.

\section{Input during the cerebral motor program}

It has recently been shown that excitation of neuron $\mathrm{C} 15$ can activate a central pattern generator $(\mathrm{CPG})$ in the isolated cerebral ganglion (Perrins and Weiss, 1996). This CPG (1) drives a cerebral motor program (CMP), which includes rhythmic activity in lip motoneurons, and (2) interacts in a variety of ways with buccal feeding circuitry. During this CMP, input to CBI-5/6 consisted of a phase in which it received a barrage of fast PSPs followed by a phase when no input could be observed (Fig. 6A). Although the PSPs were depolarizing from rest, they were clearly hyperpolarizing from the level of the plateau potential (Fig. $6 B, C)$. They probably represent dual-component fast excitatory and inhibitory PSPs (E/IPSPs) and strongly resembled those described for the connection between neurons B4 and B7 in the buccal ganglion (Gardner and Kandel, 1972). A barrage of the E/IPSPs elicited during a current-induced plateau potential in CBI-5/6 led to the early termination of the plateau (Fig. $6 B$ ). In 2 of 17 preparations the PSPs could also drive CBI-5/6 into the plateau potential from rest (Fig. $6 C$ ). This input can, therefore, under some circumstances both initiate and terminate the plateau.

\section{Connections of $\mathrm{CBI}-5 / 6$ with buccal feeding circuitry}

We investigated the presynaptic and postsynaptic connections of CBI-5/6 with a number of buccal neurons involved in feeding behaviors. Firing in the buccal-to-cerebral interneurons (BCIs) (Rosen et al., 1990, 1991a), B18 and B19 resulted in fast EPSPs in CBI-5/6 (Fig. 7; see Fig. 12A). These EPSPs could summate to drive CBI-5/6 into a plateau potential (Fig. $7 A$ ).

Firing in CBI-5/6 produced by current injection at the soma resulted in PSPs in a variety of buccal neurons (Fig. 8; see Fig. 12). Fast EPSPs were observed in the putative pattern generator neuron B64 (Hurwitz and Susswein, 1996) and the multifunction neuron B4 (Fig. 8A). An electrical coupling from B4 to CBI-5/6 could also be observed (Fig. $8 B$ ). Although apparently weak (coupling ratio, 0.04-0.07), the site of the coupling is presumably in the buccal ganglia (because B4 has no processes extending through the $\mathrm{CBC}$ ) and significant degradation of the signal must occur along the axon of CBI-5/6. Therefore the local coupling at the buccal processes and terminals of $\mathrm{CBI}-5 / 6$ could be functionally quite powerful. No coupling could be seen when negative current was injected into the soma of CBI-5/6, possibly because of the large size of B4 compared with CBI-5/6. The BCI B19 also received EPSPs in response to firing in CBI-5/6 (Fig. $8 D$ ). Regularly occurring IPSPs $(1-2 \mathrm{~Hz})$ received by some buccal neurons ceased briefly after activity in CBI-5/6 (Fig. 8D,E), presumably because of inhibition of an unidentified presynaptic neuron by CBI-5/6.

At the motoneuron level orthodromic firing in CBI-5/6 produced fast EPSPs and IPSPs in several neurons in the ventral motoneuron cluster of the buccal ganglion. Figure $8 C$ shows examples of IPSPs in an unidentified motoneuron and EPSPs received by $\mathrm{B} 15$. The fast $\mathrm{PSPs}$ observed in buccal neurons could occasionally be seen to be one-for-one with spikes in CBI-5/6 (Fig. 8A), although more often this was difficult to determine because of the multiple spike-like potentials resulting from the electrotonic transfer of spikes in the neighboring CBI-5/6 and CPN1 (Fig. 8C-E). 


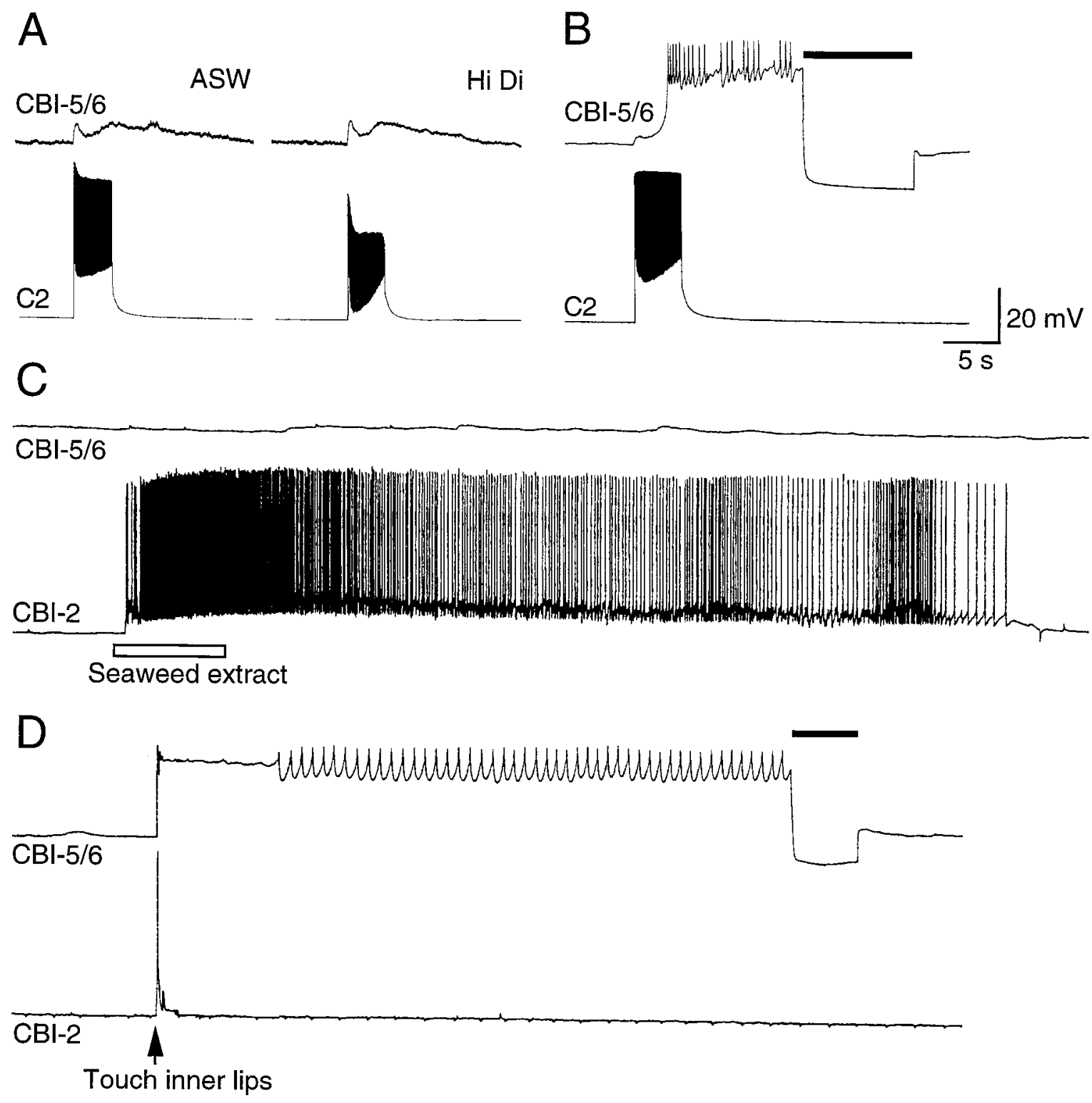

Figure 5. Inputs from the lips to CBI-5/6. A, Lip mechanoafferent $\mathrm{C} 2$ produced a biphasic excitation of CBI-5/6, which was not blocked in a high-divalent solution. $B$, Longer stimulation of $\mathrm{C} 2$ drove $\mathrm{CBI}-5 / 6$ into a plateau potential (terminated by a hyperpolarizing current pulse indicated by the bar). $C$, In a preparation of the head and cerebral ganglion, chemical stimuli (seaweed extract) applied to the lips strongly excited CBI-2 but had little effect on CBI-5/6. D, A brief mechanical stimulus to the lips briefly depolarized CBI-2 and drove CBI-5/6 into a plateau (terminated by a negative current pulse indicated by the solid bar).

\section{Activity of CBI-5/6 during BMPs}

Because CBI-5/6 made connections with elements of buccal and cerebral feeding circuitry, we investigated the activity of CBI-5/6 during two distinct evoked BMPs to discover at what phase during feeding these synapses may be active. An ingestive-like BMP was driven by intracellular excitation of CBI-2 (Rosen et al., 1991b; Church and Lloyd, 1994), whereas an egestive-like BMP was driven by low-frequency electrical stimulation of the esophageal nerve (Morton and Chiel, 1993). The ingestive and egestive nature of the BMPs was monitored using neurons B4 and B8 (Church and Lloyd, 1994). During both types of BMP, CBI-5/6 showed three phases of input recorded from the soma.

Phase 1

During the phase associated with protraction of the radula in both BMPs CBI-5/6 received a barrage of PSPs. These increased in amplitude when CBI-5/6 was hyperpolarized (Fig. 9). As with the PSPs recorded during the CMP, these PSPs were depolarizing from rest but hyperpolarizing from the plateau (Fig. 9) and are thus E/IPSPs. The summation of these E/IPSPs was decreased by hyperpolarization attributed to inward rectification in CBI-5/6 that reduced EPSP fall time. The E/IPSPs were chemical in nature, because they were blocked when a solution containing zero $\mathrm{Ca}^{2+}$ and $10 \mathrm{mM} \mathrm{Co}^{2+}$ was applied to the cerebral ganglion (Fig. 10).

\section{Phase 2}

During the phase associated with radula retraction, the soma of CBI-5/6 received a series of potentials that had a similar appearance to chemical PSPs. However, unlike the E/IPSPs, these potentials were reduced in amplitude when the soma of CBI-5/6 was hyperpolarized (Figs. 9, 10). Additionally, when a solution 

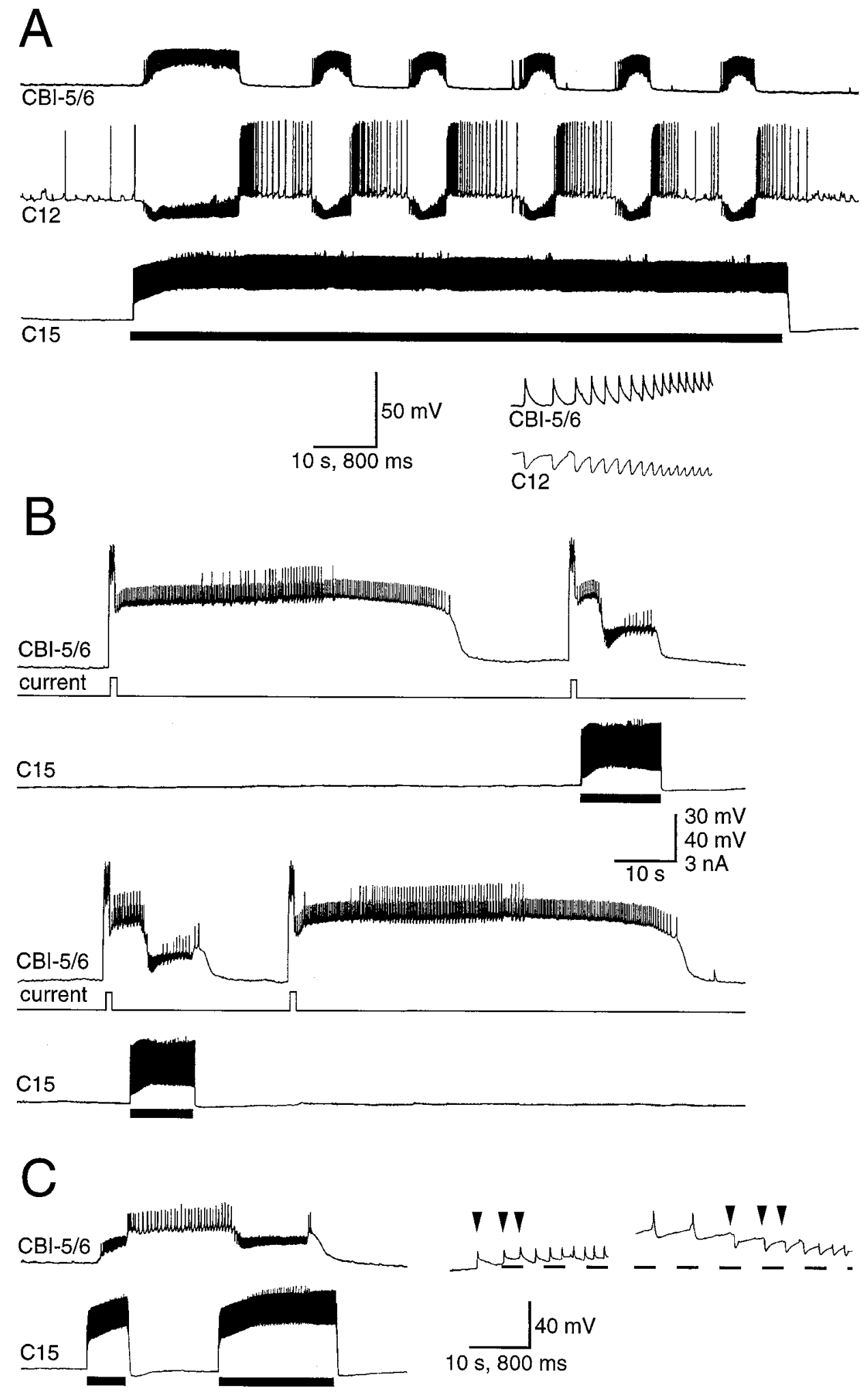

Figure 6. Input to CBI-5/6 during the CMP. $A$, The CMP was driven by injecting tonic depolarizing current into C15 (solid bar). The input to CBI-5/6 consisted of barrages of fast PSPs that were one-for-one with the fast IPSPs in lip motoneuron C12 (time-expanded bottom trace). $B$, A brief depolarizing current pulse in CBI-5/6 gave rise to a plateau potential that spontaneously terminated after $54 \mathrm{sec}$, and the next two plateau potentials terminated early (after 13-14 sec), after PSPs received during one cycle of the CMP driven by depolarization of C15 (shown by bar). A forth plateau terminated spontaneously after $62 \mathrm{sec}$. Records are consecutive. $C$, An example in which the plateau potential in CBI-5/6 could be both terminated and terminated by E/IPSPs during the CMP. A first cycle of the CMP produced by current in C15 ( first bar) resulted in depolarizing E/IPSPs in CBI-5/6 that drove it into a plateau. A second cycle (second bar) terminated the plateau. The faster time base records to the right show that the E/IPSPs (the first three PSPs of each CMP cycle are indicated by the arrowheads) were depolarizing from rest ( $-54 \mathrm{mV}$ in this case) but hyperpolarizing from the plateau potential $(-29 \mathrm{mV})$. 

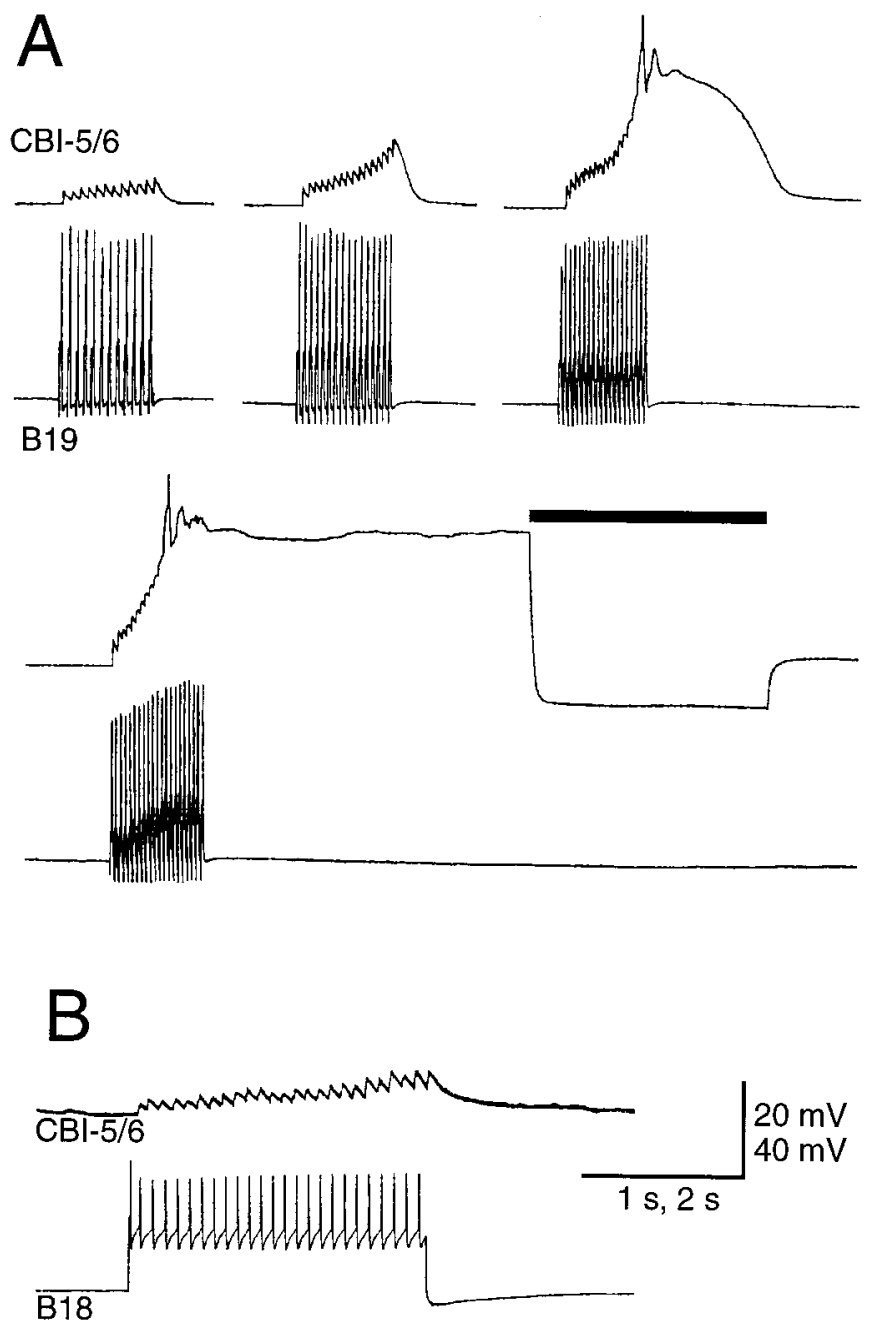

Figure 7. A, Spikes in buccal-to-cerebral interneuron B19 produced fast one-for-one EPSPs in CBI-5/6. At $37 \mathrm{~Hz}$, the EPSPs summate sufficiently to drive CBI-5/6 into a sustained plateau potential (terminated by a hyperpolarizing current pulse indicated by the bar). Note that CBI-5/6 did not fire during the plateau. $B$, Spikes in buccal-to-cerebral interneuron B18 produced fast EPSPs in CBI-5/6 that could also drive it into the plateau (data not shown).

with zero $\mathrm{Ca}^{2+}$ and $10 \mathrm{~mm} \mathrm{Co}^{2+}$ was applied to the cerebral ganglion, this second phase remained (Fig. 10), indicating that the potentials were not due to transmitter release in the cerebral ganglion. In zero $\mathrm{Ca}^{2+}$ and $10 \mathrm{mM} \mathrm{Co}^{2+}$ these potentials were again reduced by hyperpolarization of CBI-5/6. These results suggest that phase 2 consists of a barrage of axon spikes (Aspikes) arriving antidromically from the distal processes in the buccal ganglion. Similar potentials could be obtained using electrical stimulation of the $\mathrm{CBCs}$, which were also reduced by hyperpolarization (Fig. 11A) and not blocked in zero $\mathrm{Ca}^{2+}$ and $10 \mathrm{~mm} \mathrm{Co}^{2+}$. Although the amplitude of the potentials during phase 2 could be reduced by hyperpolarization, their frequency was not altered (maximum of $20-25 \mathrm{~Hz}$; Fig. $11 B_{1}, B_{2}$ ). This was probably because the buccal spike initiation site was too distant to be affected by current injected into the soma. We attempted to use en passant suction electrode on the $\mathrm{CBC}$ to identify one-forone extracellular spikes with the potentials of phase 2. Although we could identify orthodromic spikes after current injected into the cell body of $\mathrm{CBI}-5 / 6$, there was too much activity in the $\mathrm{CBC}$
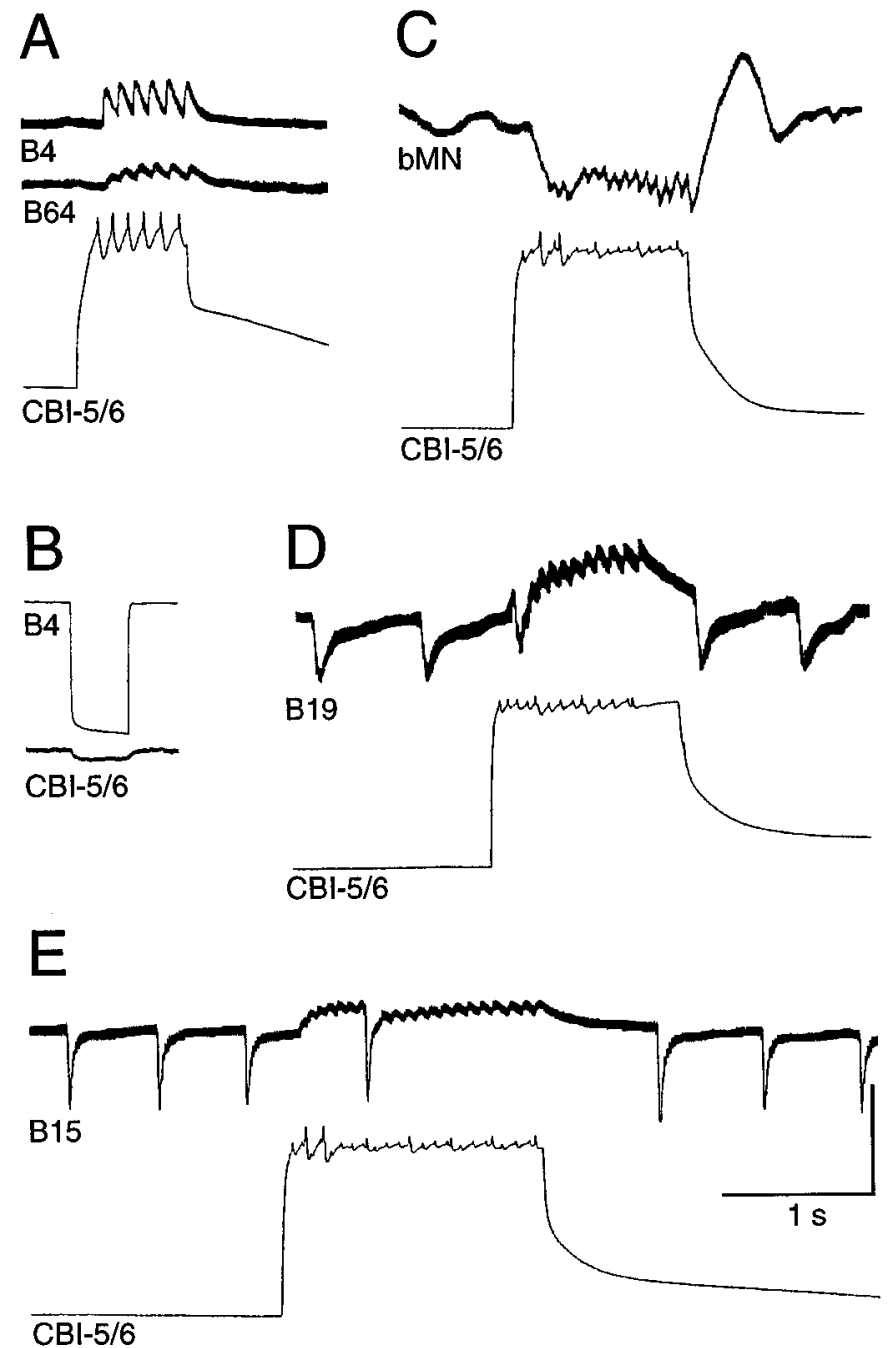

Figure 8. CBI-5/6 makes synapses onto buccal motor and premotor neurons involved in feeding-related motor programs. $A$, Spikes in CBI-5/6 were followed one-for-one by fast EPSPs in premotor neurons B4 and B64. B, A hyperpolarizing current pulse injected into B4 resulted in hyperpolarization of CBI-5/6. This electrical coupling was probably strong in the buccal ganglion, but the signal was weakened while traveling along the axon of CBI-5/6 from buccal to cerebral ganglia. $C$, Spiking in CBI-5/6 produced fast IPSPs in an unidentified buccal motoneuron $(b M N) . D$, Spiking in CBI-5/6 produced fast EPSPs in B19. $E$, Spiking in CBI-5/6 produced fast EPSPs in buccal motoneuron B15. For $D$ and $E$ note that the regularly occurring IPSPs in B19 and B15 were briefly eliminated by firing in CBI-5/6. For all records CBI-5/6 was held hyperpolarized from rest to prevent the activation of a plateau potential after current injection. Note for records in $C-E$ that it is difficult to judge whether the PSPs are one-for-one with spikes in CBI-5/6 because of multiple spike-like events caused by electrical coupling to other neurons. Scale bars: CBI-5/6 in $A, C-E$, B4 in $B, 40 \mathrm{mV}$; all buccal neurons in $A, C$, $D$, CBI-5/6 in $B, 10 \mathrm{mV}$.

(from BCIs and other CBIs) during BMPs to distinguish antidromic spikes extracellularly during phase 2 .

\section{Phase 3}

During this phase most other neurons recorded were silent, and this probably represents the pause between each cycle of activity. In 3 of 15 preparations the membrane potential of CBI-5/6 returned to the resting potential, and no obvious inputs were observed. In the remaining cases a plateau potential was gener- 

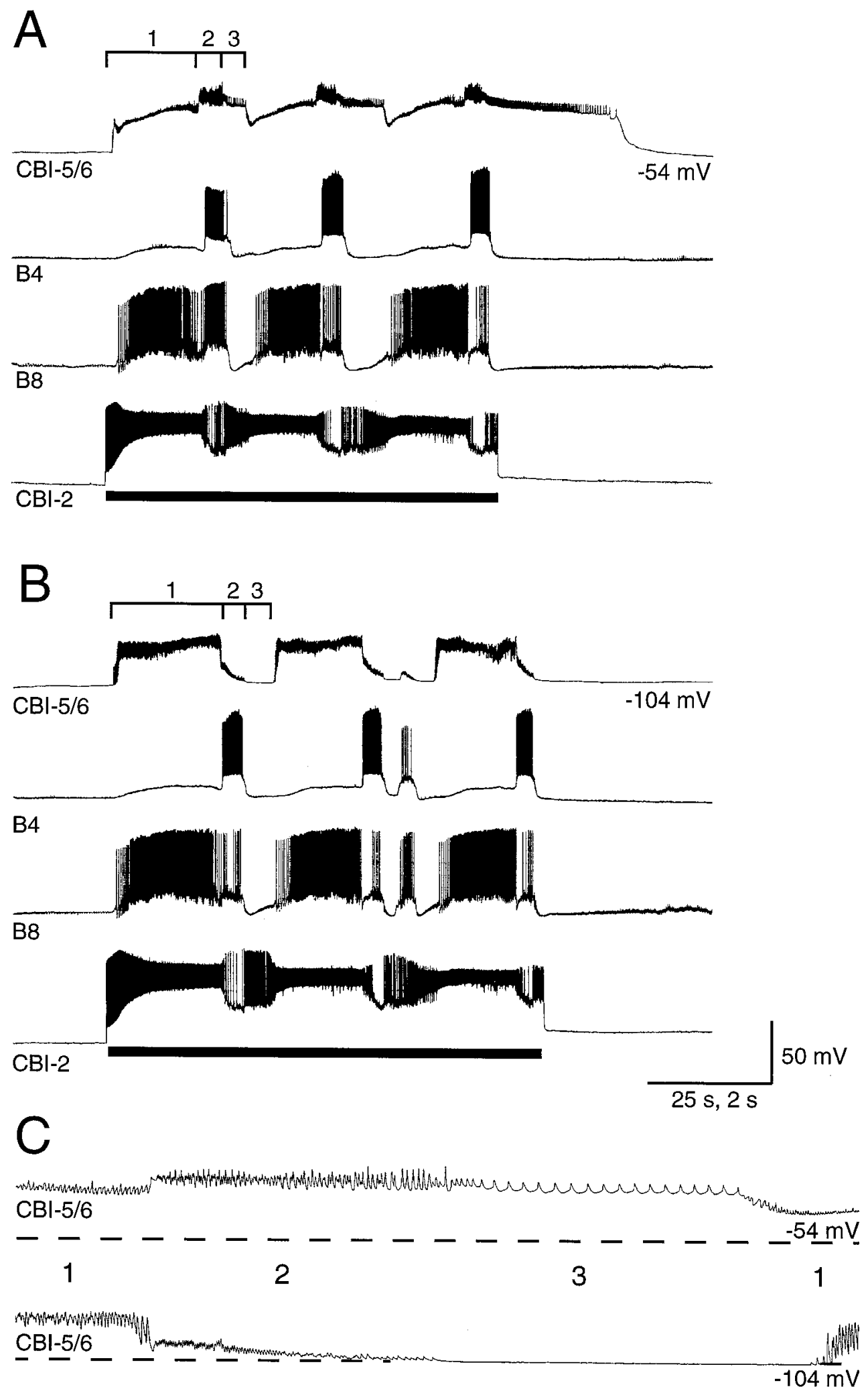

Figure 9. Input onto CBI-5/6, recorded from the soma, during an ingestive-like BMP. $A$, Three cycles of a BMP were driven by injecting constant current into CBI-2 (bar). This incorporated rhythmic firing in buccal neurons B4 and B8. CBI-5/6 received input during the BMP that could be divided into three phases (labeled 1-3). Phase 1 coincided with the buildup of excitation in B8. Phase 2 took place during firing in B4, and phase 3 coincided with a period of little activity in either neuron. CBI-5/6 remained in the plateau of the final phase 3 for 30 sec after the BMP stopped. $B$, With CBI-5/6 hyperpolarized by $50 \mathrm{mV}$, a BMP could still be driven by CBI-2. Each phase of input to CBI-5/6 was altered in a characteristic way by hyperpolarization. The potentials in phase 1 were increased in amplitude, whereas those in phase 2 were reduced in amplitude. No activity or input could be seen in CBI-5/6 during phase 3 . The activity of CBI-5/6 in each phase is seen best in the bottom time-expanded record in C. Dashed lines in $C$ represent the membrane potential before the start of the BMP. 
A
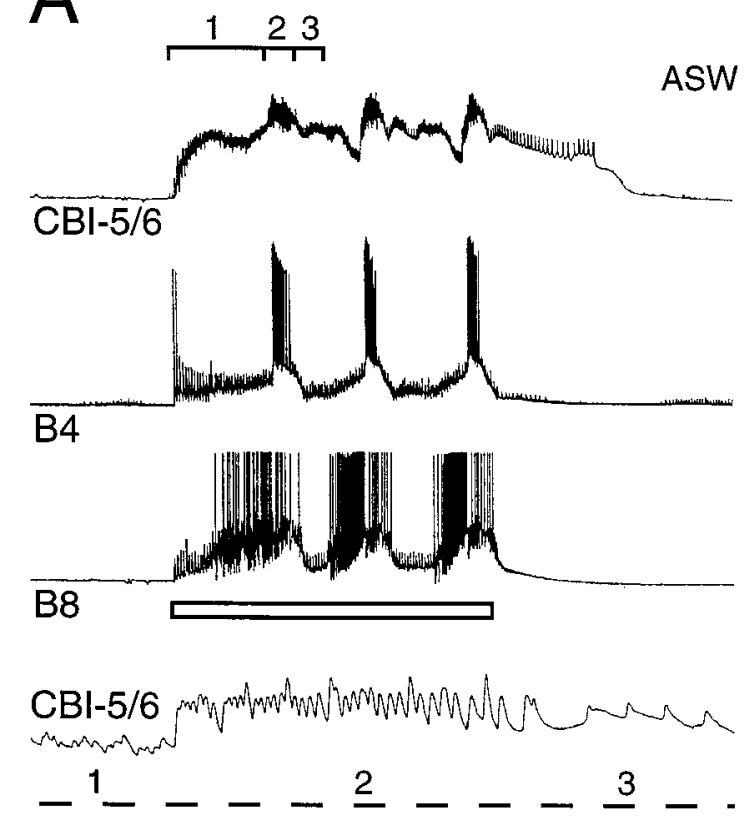

C

$0 \mathrm{Ca}^{2+/ 10} \mathrm{mM} \mathrm{Co}^{2+}$
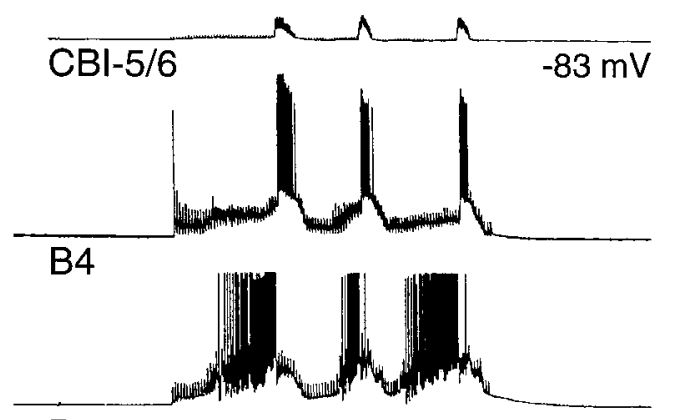

B8

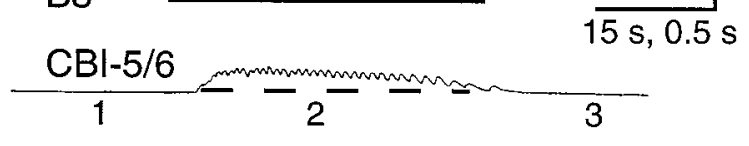

B

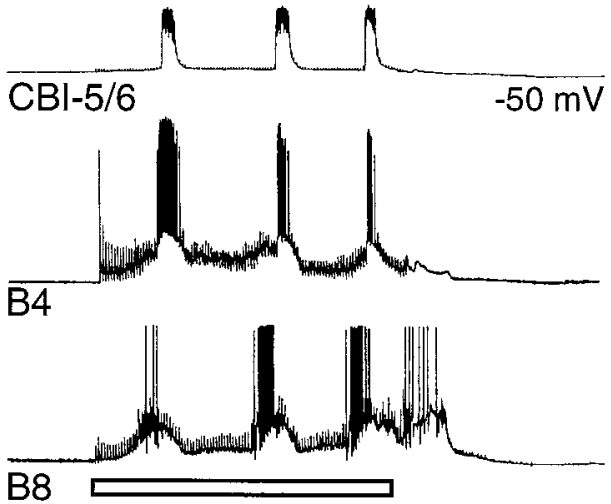

CBI-5/6

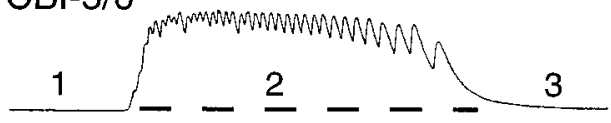

D

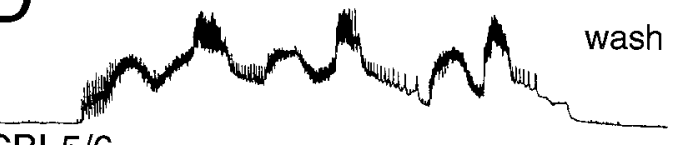

$\mathrm{CBI}-5 / 6$

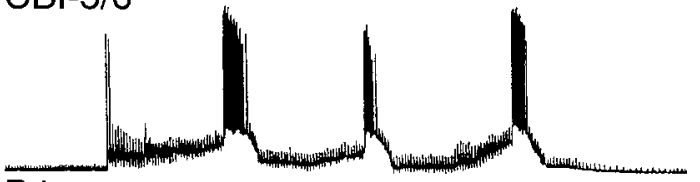

B4

$50 \mathrm{mV}$

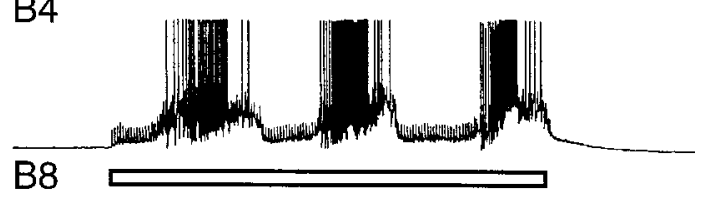

B8

Figure 10. Effects of blocking chemical transmission in the cerebral ganglion on the input to the soma of CBI-5/6. A, Three cycles of an egestive-like BMP were driven by repetitive electrical stimulation of the esophageal nerve (at $2.5 \mathrm{~Hz}$; open bar). This BMP incorporated firing in B8 and B4. As with the ingestive-like BMP, three phases in input to CBI-5/6 can be distinguished, with phase 2 coinciding with firing in B4. Phase 2 in CBI-5/6 from the third cycle is shown at a faster time base in the lowest trace, as it also is for $B$ and $C$. $B$, The cerebral ganglion was bathed in a solution containing 0 mM $\mathrm{Ca}^{2+}$ and $11 \mathrm{mM} \mathrm{Co}^{2+}$ to block chemical transmission. Because transmission in the buccal ganglion was unaffected, the BMP could still be driven by esophageal nerve stimulation, and a similar pattern of firing to control occurred in B8 and B4. In CBI-5/6, however, the potentials of phase 1 and the firing during phase 3 were completely blocked. The barrage of fast-depolarizing potentials during phase 2 remained largely unaffected, although they appear to be more regular than in control, indicating that some chemical input may have been blocked. The remaining potentials probably represent A-spikes originating in the buccal ganglion (see Results for details). $C$, When CBI-5/6 was hyperpolarized by $33 \mathrm{mV}$, there was still no observable input during phases 1 and 3 , and the potentials of phase 2 were reduced in amplitude, although their frequency was not affected. $D$, All three phases of input to $\mathrm{CBI}-5 / 6$ were clearly seen again during wash.

ated during phase 3 . The level of depolarization and firing rate of CBI-5/6 during phase 3 was similar to that recorded during current-evoked plateau potentials (Fig. $11 B_{1}$ and $B_{2}$ ). Constant hyperpolarizing current injected into $\mathrm{CBI}-5 / 6$ resulted in complete blockage of the plateau potential during phase 3. Under these conditions no synaptic inputs were observed during this phase, suggesting that the plateau potential is a result of intrinsic cellular properties after the A-spikes.

\section{DISCUSSION}

\section{Is $\mathrm{CBI}-5 / 6$ part of the feeding rhythm} generating circuitry?

We have three strong lines of evidence that activity in CBI-5/6 is important during feeding-related motor programs: (1) CBI-5/6 is excited by feeding-related stimuli; (2) CBI-5/6 synapses onto buccal motor and premotor circuitry; and (3) CBI-5/6 is phasically active during BMPs. 


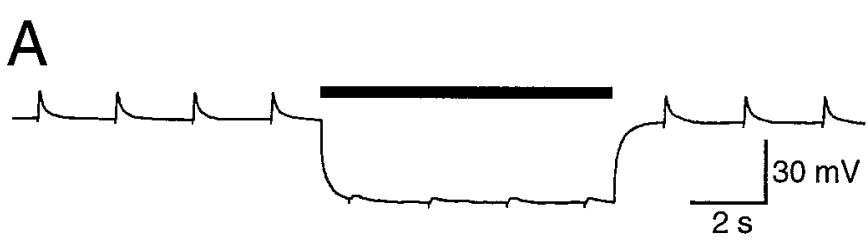

$\mathrm{B}_{1}$

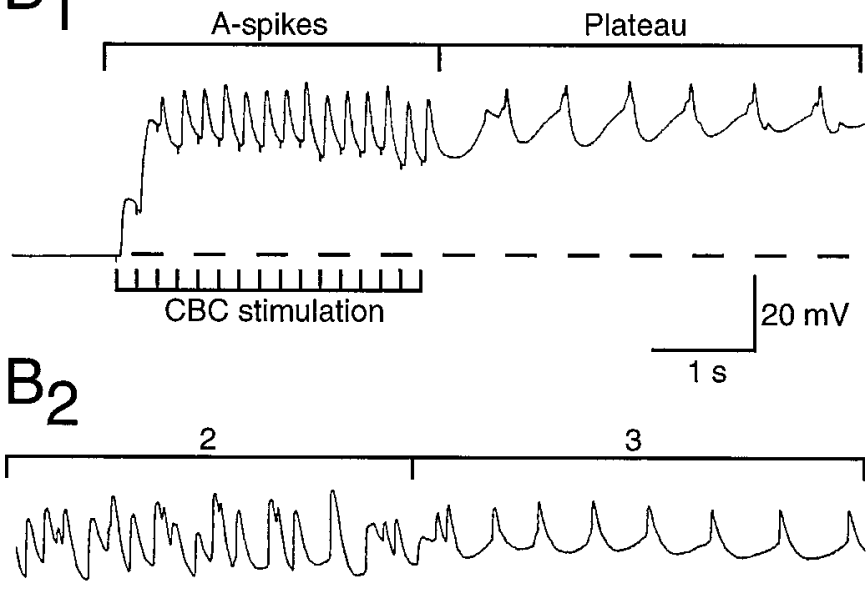

Figure 11. The characteristics of A-spikes in CBI-5/6 in response to electrical stimulation of the cerebral-to-buccal connective (CBC). $A$, The $\mathrm{CBC}$ was stimulated at $0.5 \mathrm{~Hz}$ (a small stimulus artifact can be seen as a downward deflection in the CBI-5/6 trace), producing A-spikes in CBI$5 / 6$. Hyperpolarization of CBI-5/6 (bar) resulted in a dramatic reduction in the amplitude of these A-spikes. Chemical EPSPs generally get larger on hyperpolarization, as they are taken farther from their reversal potential. $B_{1}$, A train of stimuli to the $\mathrm{CBC}$ (at $5 \mathrm{~Hz}$ ) led to summation of the A-spikes. The resulting depolarization was sufficient to drive CBI-5/6 into a plateau potential after termination of stimulation. $B_{2}$, The transition from phase 2 to phase 3 from a CBI-2-induced BMP in a different preparation is shown at the same scale for comparison with $B_{1}$. The potentials of phase 2 resemble the A-spikes, whereas phase 3 has a similar amplitude and firing frequency to the plateau potential.

CBI-5/6 produces EPSPs in B64, B4, B15, and B19, and it spikes antidromically at high frequencies in phase with the peak excitation in these neurons during BMPs. It therefore seems likely that spiking in the buccal processes of CBI-5/6 contributes to the excitation in these buccal neurons during BMPs.

Although antidromic firing rates of up to $25 \mathrm{~Hz}$ (Fig. 11) were recorded during feeding-like BMPs, depolarizing current injections at the soma failed to elicit firing at $>10 \mathrm{~Hz}$ (Fig. $8 A$ ). In addition, strong hyperpolarization of the soma had little effect on antidromic spike frequency, despite the dramatic reduction in spike amplitude (Figs. 9, 10). This is presumably because of the distance between the spike-initiating zones and the site of current injection. Although such features serve to emphasize the compartmentalized nature of this neuron, it limited the range of firing frequencies open to experimental manipulation from recordings at the soma. Therefore, although we found no effects of currentinduced firing or hyperpolarization of CBI-5/6 on overall buccal motor output (either in the quiescent state or during ongoing BMPs), this does not rule out profound influences of CBI-5/6 on buccal circuitry at the natural firing frequencies observed during BMPs, especially during phase 2 (up to $25 \mathrm{~Hz}$ ). Interestingly, the intrinsic properties of CBI-5/6 are quite distinct from those of other CBIs. Indeed, they have more in common (plateau potentials, electrically coupled followers, and nonovershooting spikes observed in the soma) with neurons thought to be involved in the buccal CPG of Aplysia, such as B31/B32 (Susswein and Byrne, 1988), B51 (Plummer and Kirk, 1990), and B64 (Hurwitz et al., 1994).

\section{Spike initiation in $\mathrm{CBI}-5 / 6$}

The orthodromic spikes in CBI-5/6 recorded from the soma were quite small, perhaps caused by a cerebral spike initiation zone of CBI-5/6 at a relatively large distance from the soma, which itself is inexcitable. Why is this the case, when the majority of Aplysia neurons have active somata? If the main role of the plateau potential is to produce an even depolarization in CPN1 and other electrically coupled neurons, then the electrotonic transfer of full soma spikes in CBI-5/6 would disrupt this (B31/B32; Hurwitz et al., 1994). It is also possible that a relatively distant orthodromic spike initiation zone allows for large depolarizations at the soma (during plateau potentials) without giving rise to high-frequency firing. Both these functional possibilities would contribute to the compartmentalization of information flow (see below).

The antidromic spikes observed during phase 2 of BMPs indicate that there is also a spike initiation zone even farther from the soma, probably in the distal processes of CBI-5/6 in the buccal ganglion. The axon of CBI-5/6 thus conveys spikes in both directions during BMPs. We have called these orthodromic and antidromic, because the only possible terms, somatopetal and somatof ugal (Nagy et al., 1981), are not widely used. A few cases of two or more spike initiation zones in different ganglia being centrally activated during a rhythmic motor program have been described in the stomatogastric system (Vedel and Moulins, 1978; Moulins et al., 1979), but this is the first case such a situation has been shown in Aplysia.

\section{Compartmentalization of information processing in CBI-5/6}

The combination of inputs, outputs, and intrinsic properties of CBI-5/6 leads to a number of possible modes of information flow, summarized in Figure 12.

(1) Under some conditions information flow can be largely restricted to the cerebral ganglion (Fig. 12C). Mechanical stimulation of the lips excites CBI-5/6, probably partially mediated by firing in $\mathrm{C} 2$, which is a mechanosensory neuron for the inner lips (Weiss et al., 1986). Under such circumstances CBI-5/6 would relay excitation via the cell body to CPN1, without sending significant output to the buccal ganglion. Such information flow might occur at the start of feeding as seaweed is contacted but before biting begins. Once ingestive feeding is under way, C2 fires during retraction (Weiss et al., 1986), so this input would add to the depolarization from the antidromic spikes arriving at the soma of CBI-5/6 in driving the plateau potential of phase 3 . CPN1 is therefore excited by CBI-5/6 both before and during the consumatory phase of feeding. This may be important in passing on information to other systems coordinated by the ring ganglia during feeding, such as cardiovascular or locomotor circuitry. Another source of excitation to the soma of CBI-5/6 is the E/IPSPs during the CMP and phase 1 of the BMP. These PSPs quickly summate to produce an even depolarization at the soma (but generally below the threshold for the plateau or spiking; Figs. $6,10)$, which will lead to electrotonic excitation of CPN1.

(2) During phase 2 of BMPs, CBI-5/6 receives input at its distal processes, resulting in high-frequency antidromic spiking (Fig. 


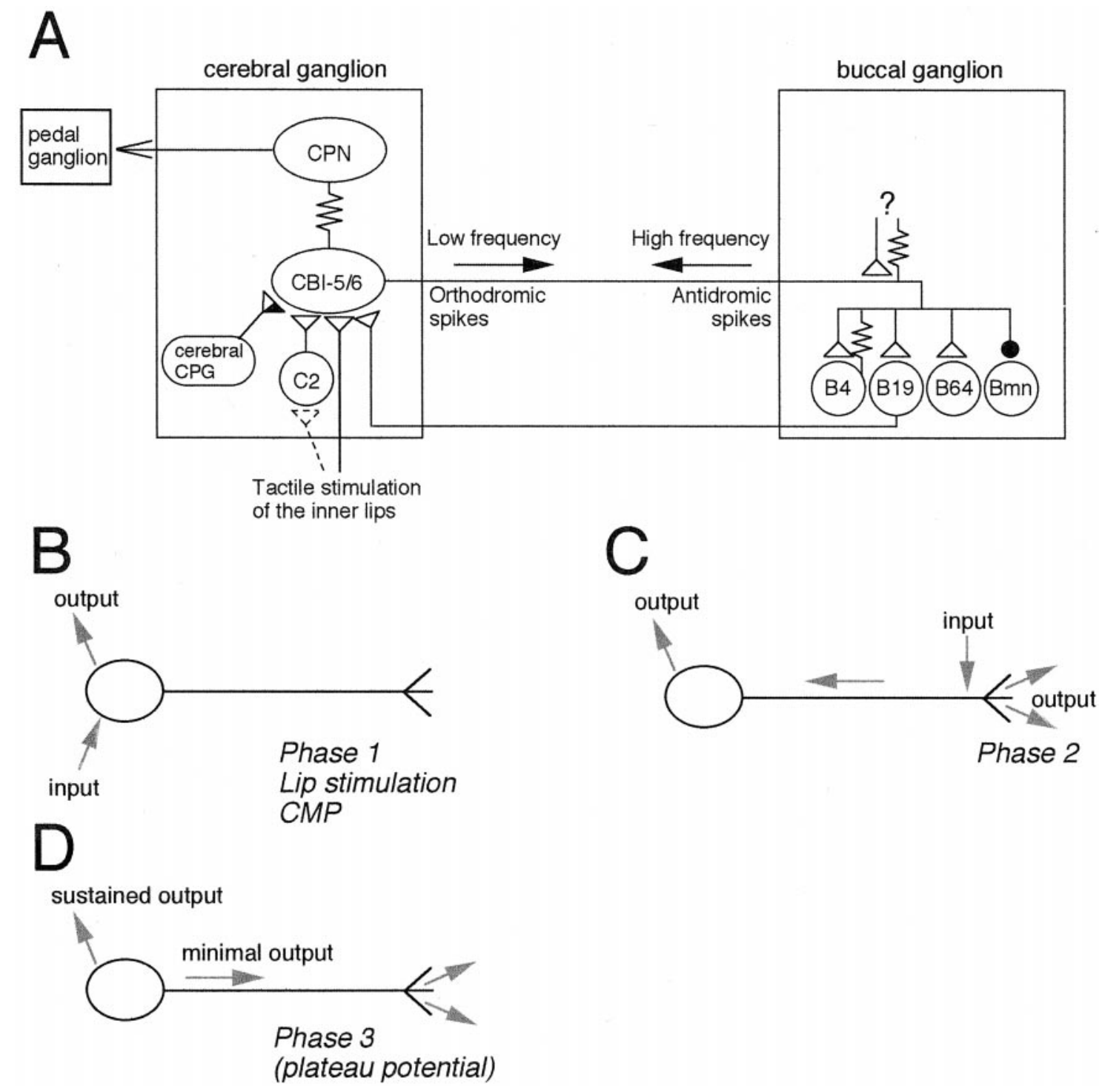

Figure 12. Summary of the cerebral and buccal connections of CBI-5/6. A, In the cerebral ganglion the soma of CBI-5/6 is electrically coupled to CPN1 and receives input from the cerebral CPG and from mechanical stimulation of the lips. This is likely to be in part mediated via excitation of mechanoafferent C2. The soma of CBI-5/6 is also excited by BCIs such as B19. In the buccal ganglion the distal processes of CBI-5/6 make chemical and electrical connections onto a variety of motor and premotor neurons of the feeding circuitry. The buccal processes are also excited either chemically or electrically from an unidentified source (?) to drive the antidromic spikes of phase 2 during BMPs. $B-D$, Different form of information flow through CBI-5/6 $B$, CBI-5/6 can process information through its soma yet have minimal influence on buccal events. This occurs whenever the soma is excited by cerebral inputs: during phase 1 of BMPs, in response to lip stimulation, and during the CMP. $C$, Input to the buccal processes generates high-frequency antidromic spiking that results in strong output in both buccal and cerebral ganglia (see Discussion for details). This occurs during phase 2 of BMPs. $D$, Once in the plateau potential (during phase 3 or in response to other sources of excitation to the soma), output from CBI-5/6 locally will be sustained without any inputs. Output in the buccal ganglion will again be low because of the low orthodromic firing rate.

12B). These processes in turn make chemical and electrical outputs onto buccal neurons. The antidromic spikes then arrive at, and depolarize, the soma of CBI-5/6. CBI-5/6 will therefore also make outputs in the cerebral ganglion, onto electrically coupled followers such as CPN1 (which may then transfer information to the pedal ganglion). In these circumstances, CBI-5/6 acts as a single unit, relaying information between ganglia, although interestingly the direction of spike propagation is opposite that conventionally observed in other neurons. A further possibility is that if the terminals of CBI-5/6 in the buccal ganglion are the subject of presynaptic inhibition similar to that seen in MCN1, then excitatory input to the buccal processes could lead to output from the soma only.
(3) During a plateau potential, CBI-5/6 will act as a sustained local source of output excitation to cerebral followers through the electrotonic transfer of the depolarization, without the need for further inputs either to the buccal processes or the cerebral soma (Fig. 12D). The output to buccal neurons will be minimal, because the orthodromic spiking frequency is low. Plateau potentials follow the antidromic spikes of phase 2 during BMPs. The rapid summation of $\mathrm{A}$-spikes in the soma of CBI-5/6 (Fig. 11B (1) $_{1}$ ) means that the generation of the plateau potential of phase 3 will be relatively independent of the firing frequency in the buccal processes during phase 2 (yet another way in which events in the two ganglia can be separated). Plateau potentials also follow the excitation in response to brief mechanical stimulation of the inner 
lips, as well as inputs from specific presynaptic neurons such as C2 and B19.

\section{General relevance of the properties of $\mathrm{CBI}-5 / 6$}

Plateau potentials are often thought of as providing a means of maintaining activity in a neuron after a brief stimulus or as a simple "switch" between two firing rates. This role is fulfilled by CBI-5/6, for example, during phase 3 of BMPs or after lip stimulation. However, this study has revealed another function for plateau potentials, in the compartmentalization of neuronal function. As long as the spike initiation zone is distant, a plateau in the soma can locally excite followers through electrical coupling while resulting in few, if any, axonal spikes. In the same neuron, spikes generated in processes in a different ganglion can be used to fulfill a quite separate role. Despite this, it is still possible to use a neuron with this combination of properties as a single unit, obviating the need for additional interneurons.

MCN1 receives input in both the commissural and stomatogastric ganglia, and the only known outputs are in the stomatogastric ganglion (Coleman and Nusbaum, 1994). OD1 receives input in commissural and esophageal ganglion, but the only known outputs are to the muscles (Nagy et al., 1981). CBI-5/6 is the first example of a neuron in which there are regions in two separate ganglia that each have distinct inputs and outputs. This characteristic, along with the intrinsic properties of CBI-5/6 lead to the novel forms of information flow shown here.

\section{REFERENCES}

Chiel HJ, Weiss KR, Kupfermann I (1986) An identified histaminergic neuron modulates feeding motor circuitry in Aplysia. J Neurosci 6:2427-2450.

Church PJ, Lloyd PE (1994) Activity of multiple identified motor neurons recorded intracellularly during evoked feeding-like motor programs in Aplysia. J Neurophysiol 72:1794-1809.

Coleman MJ, Nusbaum MP (1994) Functional consequences of compartmentalization of synaptic input. Neuroscience 14:6544-6552.

Coleman MJ, Meyrand P, Nusbaum MP (1995) A switch between two modes of synaptic transmission mediated by presynaptic inhibition. Nature 378:502-505.

Gardner D, Kandel ER (1972) Diphasic postsynaptic potential: a chemical synapse capable of mediating conjoint excitation and inhibition. Science 176:675-678.

Hartline DK, Graubard K (1992) Cellular and synaptic properties in the crustacean stomatogastric nervous system. In: Dynamic biological networks (Harris-Warrick RM, Marder E, Selverston AI, Moulins M, eds), pp 31-85. Cambridge, MA: MIT.

Hurwitz I, Susswein AJ (1996) B64, a newly identified central pattern generator element producing a phase switch from protraction to retraction in buccal motor programs of Aplysia californica. J Neurophysiol 75:1327-1344.
Hurwitz I, Goldstein RS, Susswein AJ (1994) Compartmentalization of pattern-initiation and motor functions in the B31 and B32 neurons of the buccal ganglia of Aplysia californica. J Neurophysiol 71:1514-1527.

Jahan-Parwar B, Fredman SM (1979) Cerebral ganglion of Aplysia: cellular organization and origin of nerves. Comp Biochem Physiol A 54:347-357.

Morton DW, Chiel HJ (1993) In vivo buccal nerve activity that distinguishes ingestion from rejection can be used to predict behavioral transitions in Aplysia. J Comp Physiol [A] 172:17-32.

Moulins M, Vedel JP, Nagy F (1979) Complex motor neuron in Crustacea: three axonal spike initiating zones in three different ganglia. Neurosci Lett 13:231-236.

Nagy F, Dickinson PS, Moulins M (1981) Rhythmical synaptic control of axonal conduction in a lobster motor neuron. J Neurophysiol 45:1109-1124.

Nusbaum MP, Weimann JM, Golowasch J, Marder E (1992) Presynaptic control of modulatory fibers by their neural network targets. J Neurosci 12:2706-2714.

Perrins R, Weiss KR (1996) A cerebral central pattern generator and its connections with buccal feeding circuitry in Aplysia. J Neurosci 16:7030-7045.

Plummer MR, Kirk MD (1990) Premotor neurons B51 and B52 in the buccal ganglia of Aplysia californica: synaptic connections, effects on ongoing motor rhythms, and peptide modulation. J Neurophysiol 63:539-558.

Rao G, Barnes CA, McNaughton BL (1986) Intracellular fluorescent staining with carboxyfluorescein: a rapid and reliable method for quantifying dye coupling in mammalian nervous system. J Neurosci Methods $16: 251-263$

Rosen SC, Weiss KR, Cohen JL, Kupfermann I (1982) Interganglionic cerebral-buccal mechanoafferents of Aplysia: receptive fields and synaptic connections to different classes of neuron involved in feeding behavior. J Neurophysiol 48:271-288.

Rosen SC, Halvorsen EL, Cropper EC, Miller MW, Weiss KR, Kupfermann I (1990) Neuronal control of coordinated lip movements during feeding in Aplysia. Soc Neurosci Abstr 16:1227.

Rosen SC, Weiss KR, Kupfermann I (1991a) Command of feeding in Aplysia: implication of a network of identified interganglionic interneurons in the buccal and cerebral ganglia. Soc Neurosci Abstr 17:595.

Rosen SC, Teyke T, Miller MW, Weiss KR, Kupfermann I (1991b) Identification and characterization of cerebral-to-buccal interneurons implicated in the control of motor programs associated with feeding in Aplysia. J Neurosci 11:3630-3655.

Susswein AJ, Byrne JH (1988) Identification and characterization of neurons initiating patterned neural activity in the buccal ganglion of Aplysia. J Neurosci 8:2049-2061.

Vedel JP, Moulins M (1978) A motor neuron involved in two centrally generated motor programs by means of two different spike initiating sites. Brain Res 138:347-352.

Weiss KR, Chiel HJ, Koch U, Kupfermann I (1986) Activity of an identified histaminergic neuron, and its possible role in arousal of feeding behavior in semi-intact Aplysia. J Neurosci 6:2403-2415.

Weiss KR, Chiel HJ, Kupfermann I (1986) Sensory function and gating of histaminergic neuron C2 in Aplysia. J Neurosci 6:2416-2426. 